\title{
Enantioselective Synthesis of Apoptolidin Sugars
}

Michael T. Crimmins ${ }^{\star}$ and Alan Long

Venable and Kenan Laboratories of Chemistry, Department of

Chemistry, University of North Carolina at Chapel Hill, Chapel Hill,

NC 27599-3290

crimmins@email.unc.edu

${ }^{1} \mathrm{H}$ and ${ }^{13} \mathrm{C}$ NMR spectra 

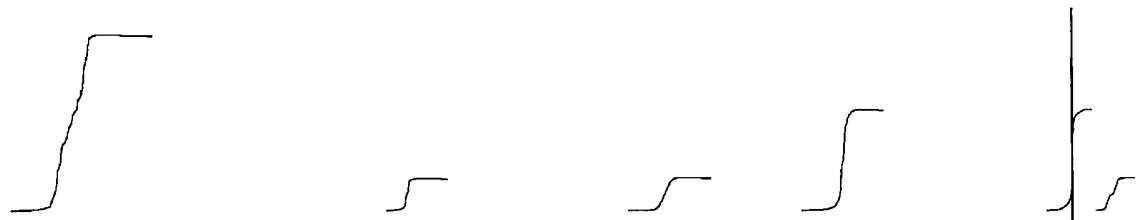<smiles></smiles>
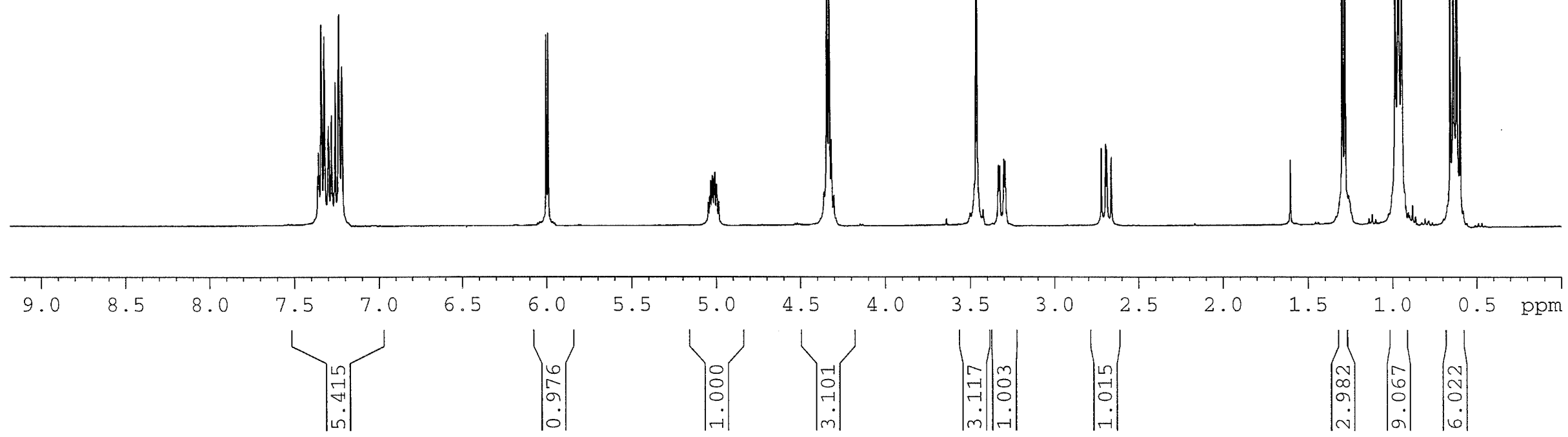


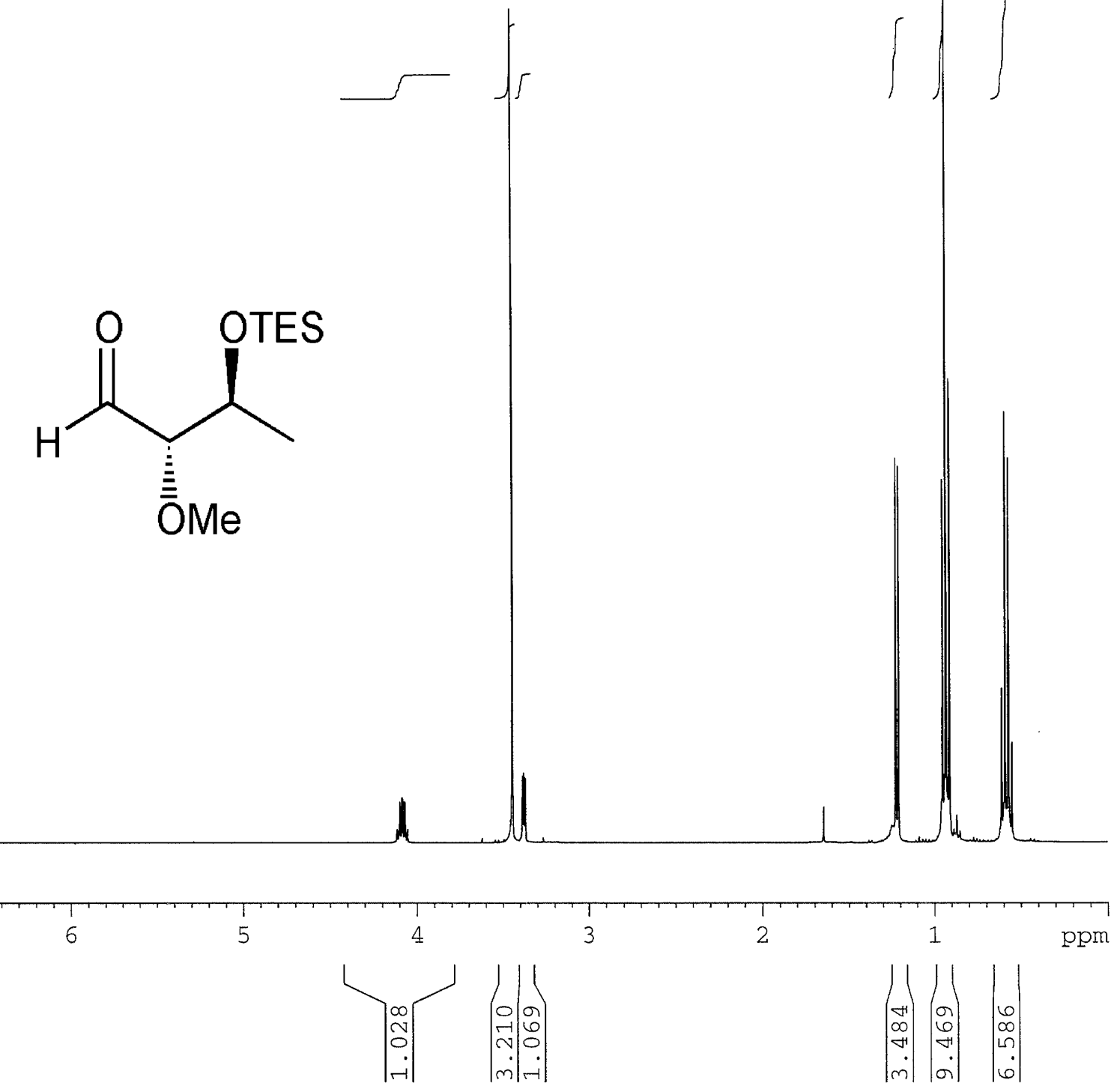




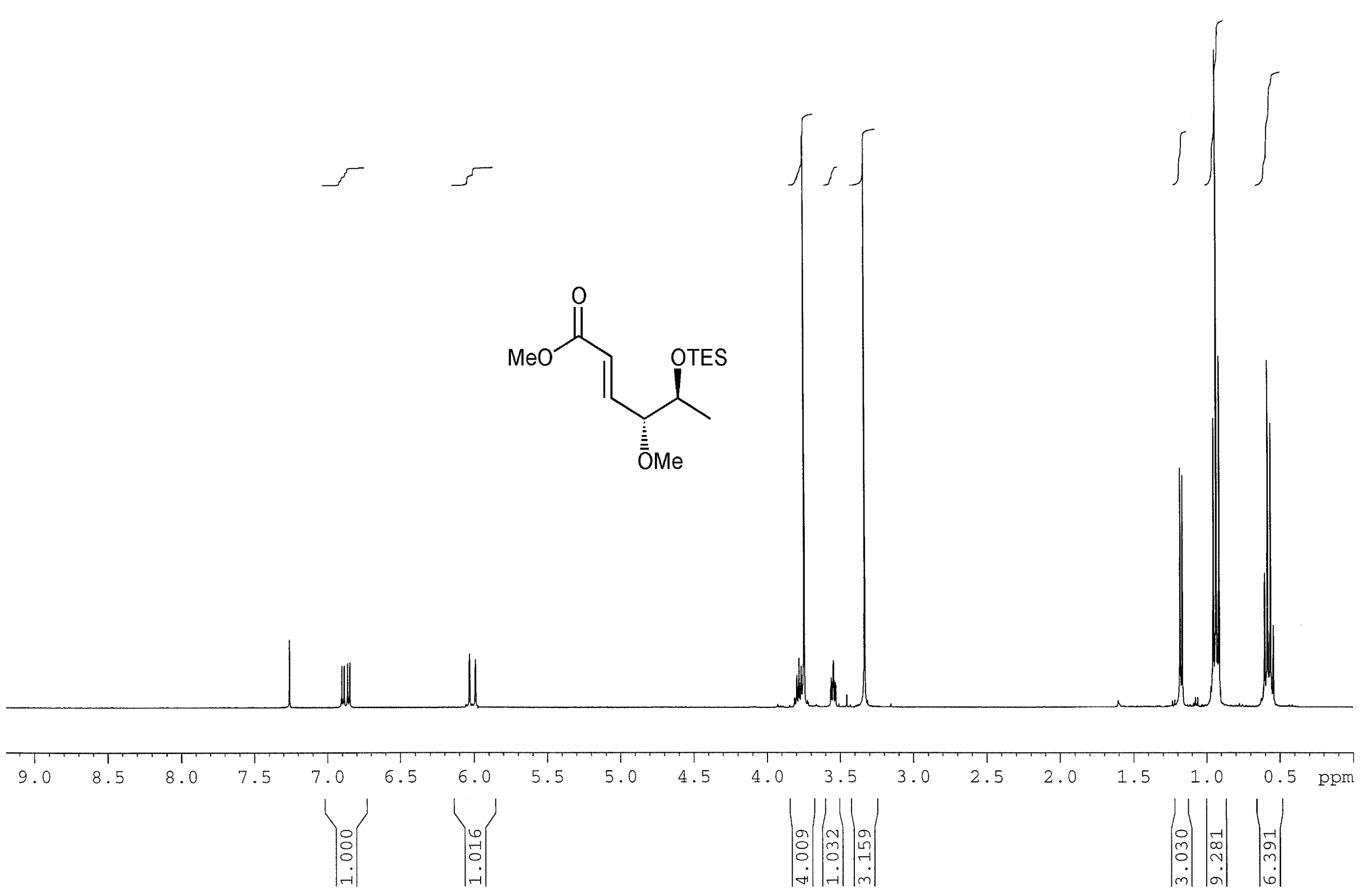




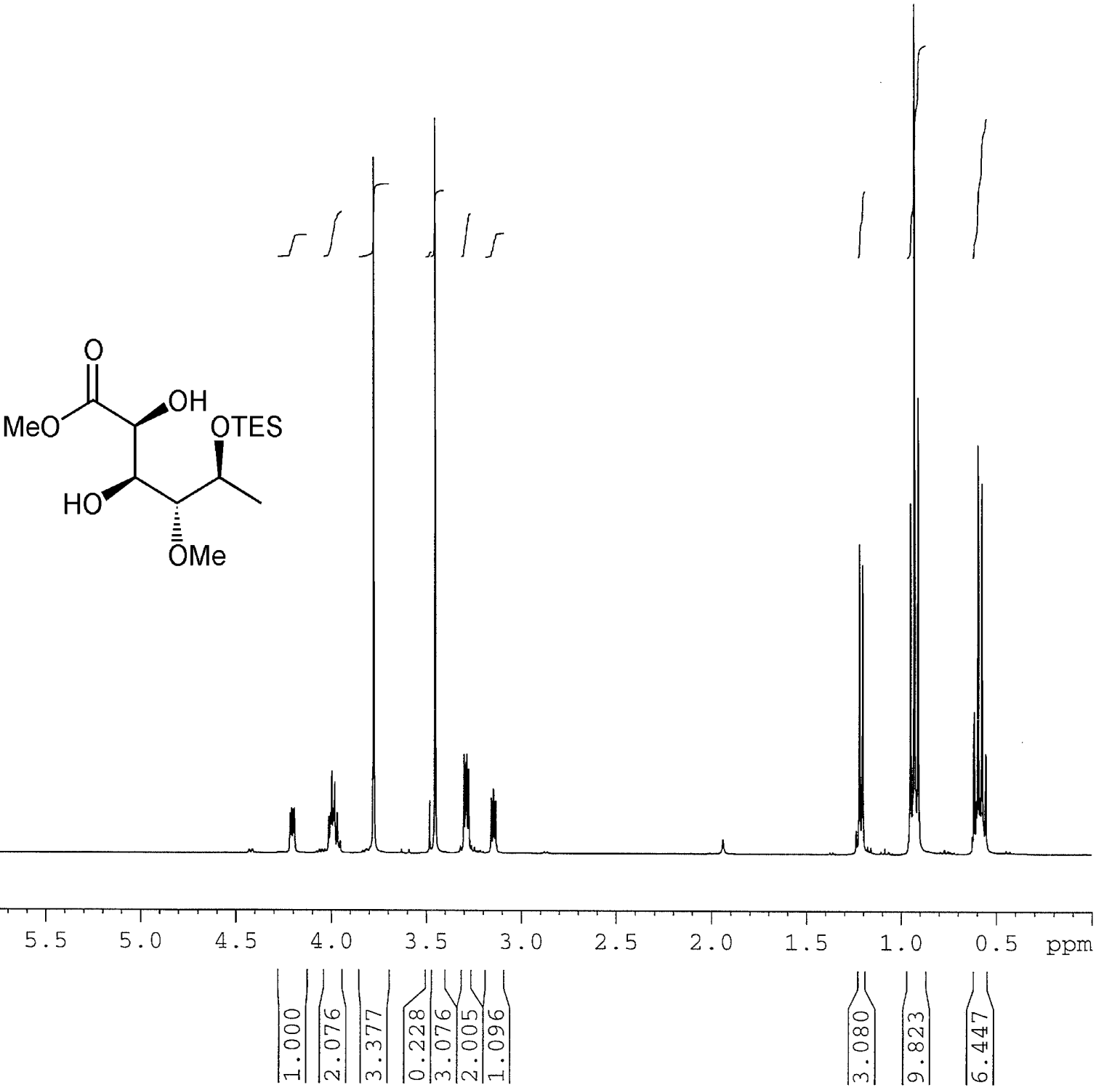




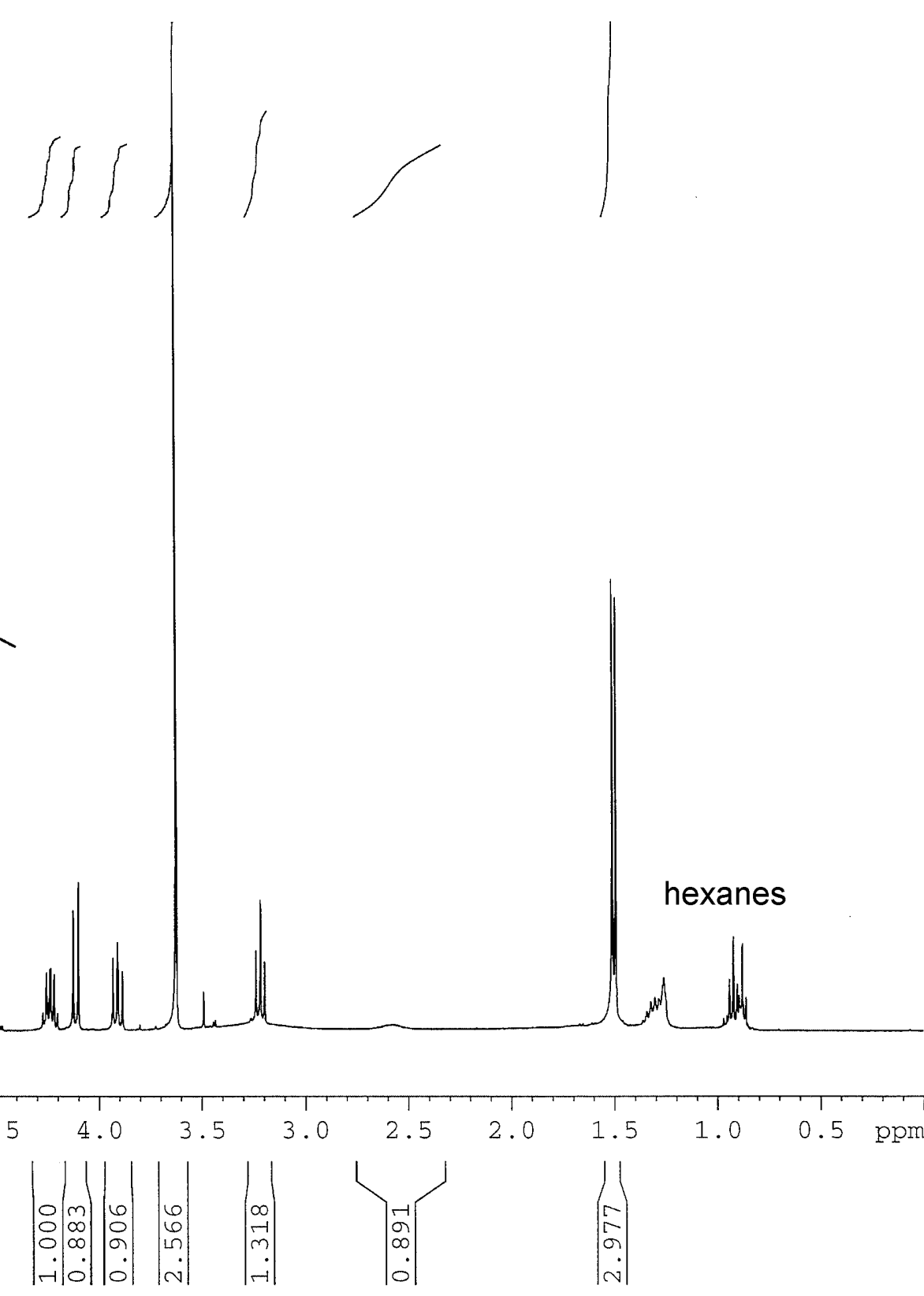


r is

is

S1 S1
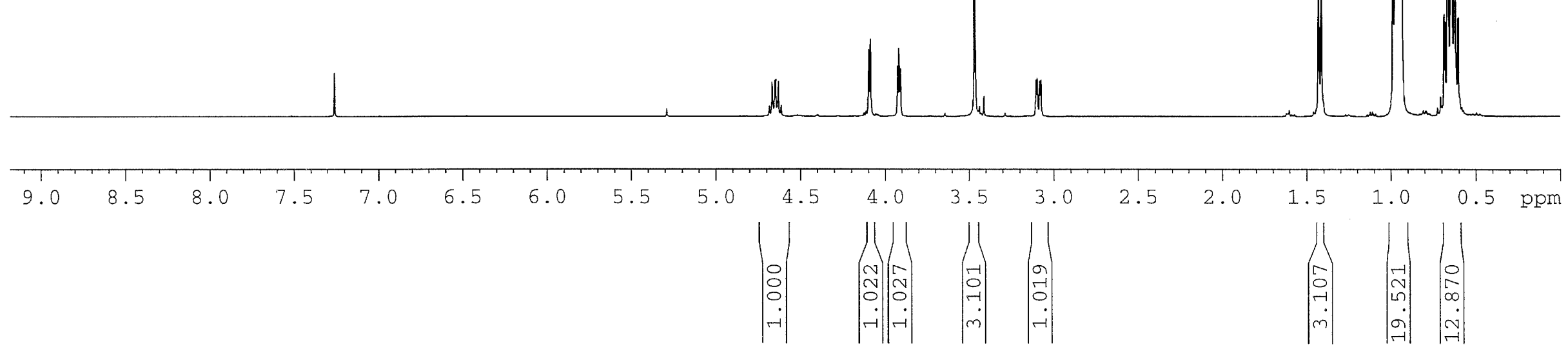


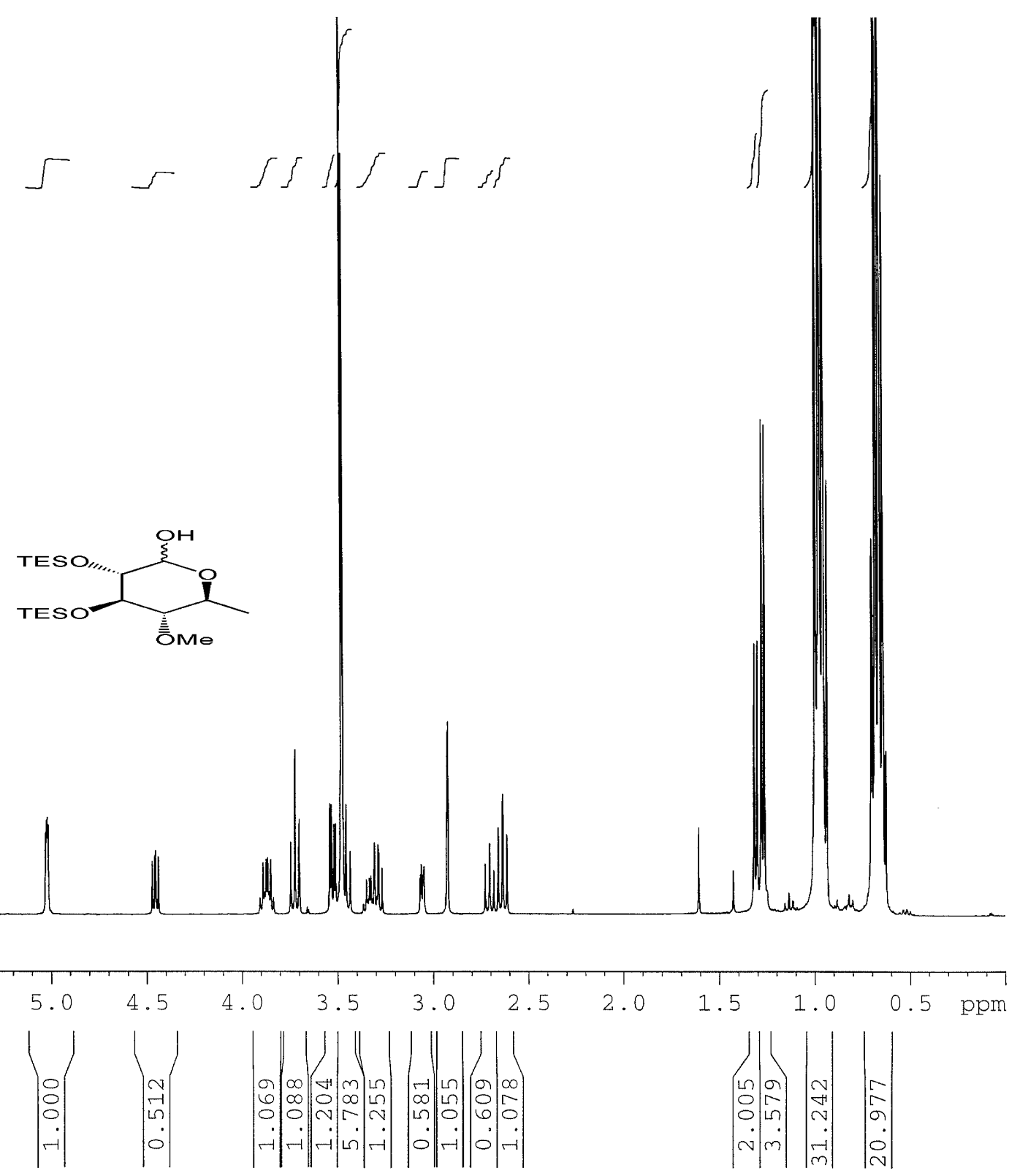


$\int \sin \|/\| \mathrm{S} / 4$

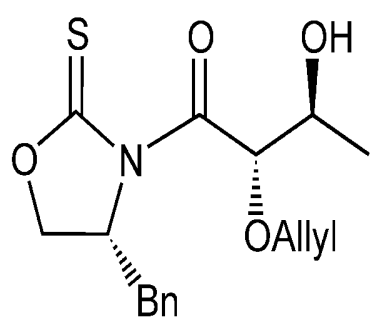

$\bar{\sigma}$
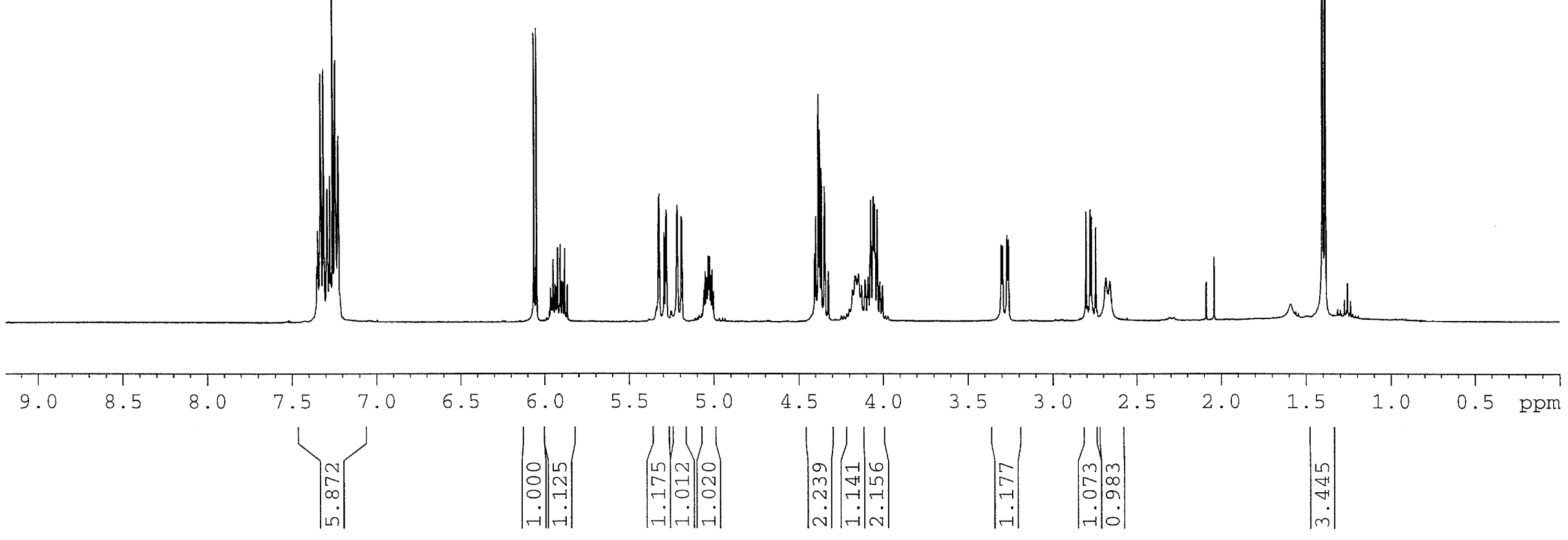


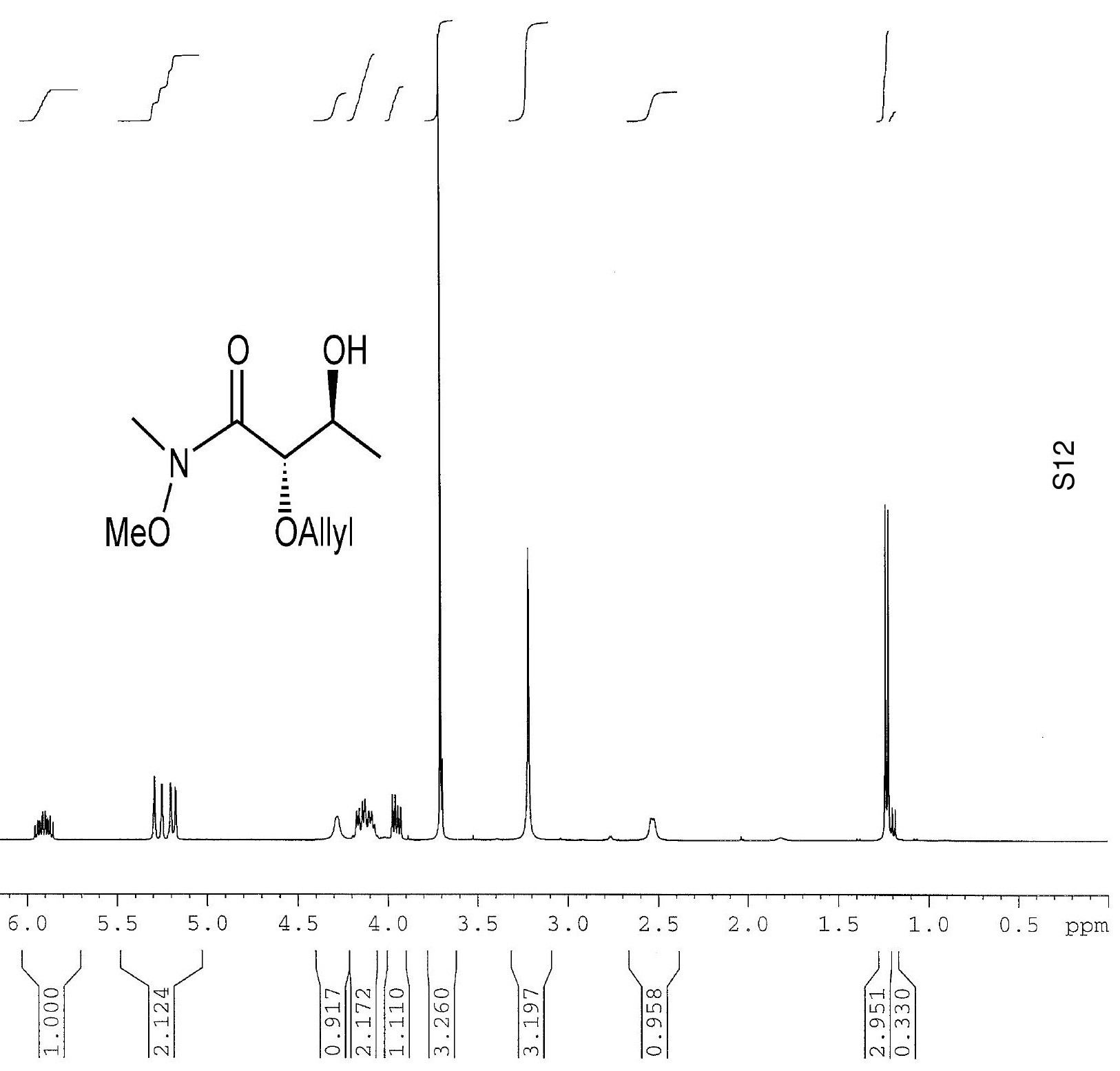




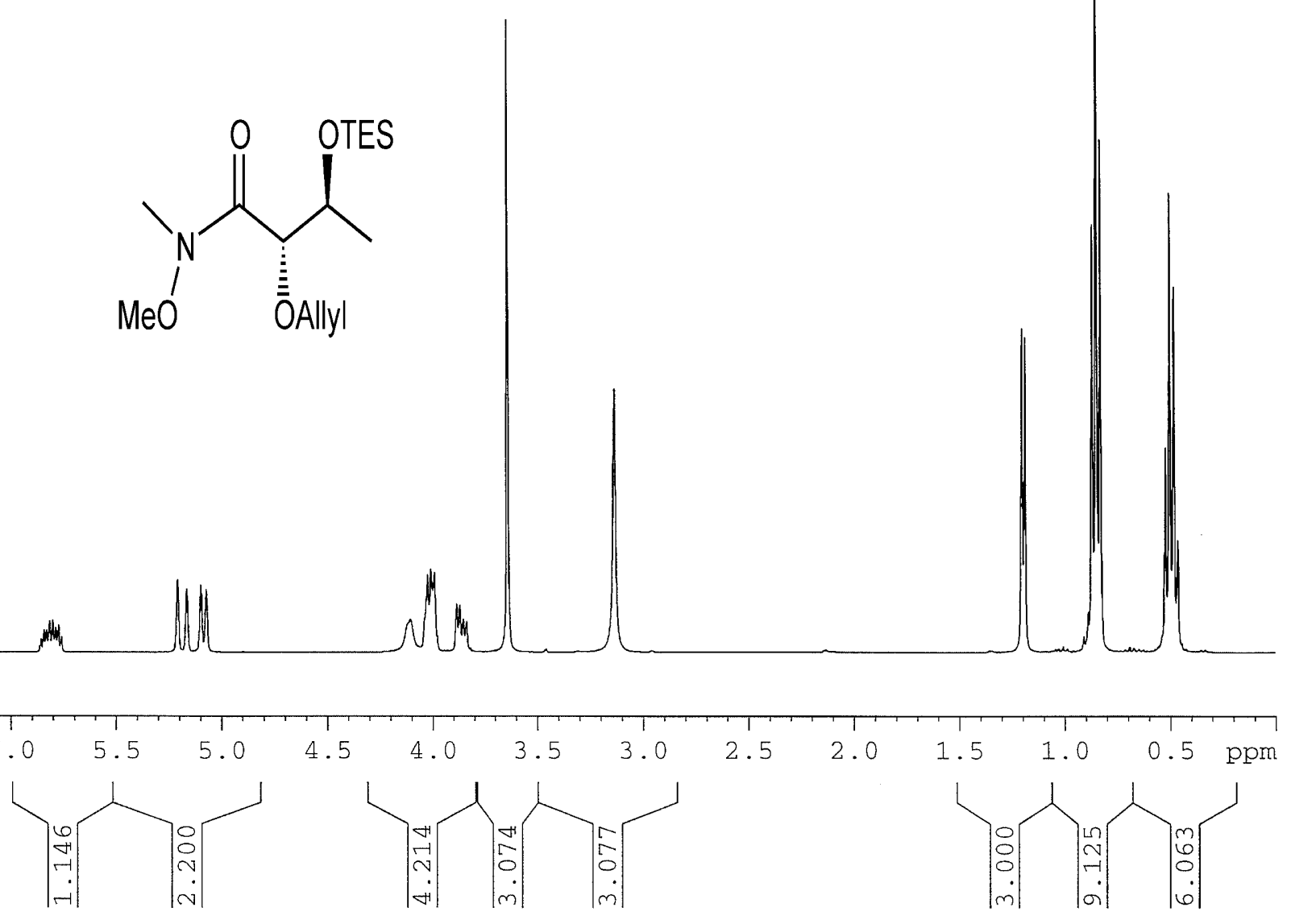




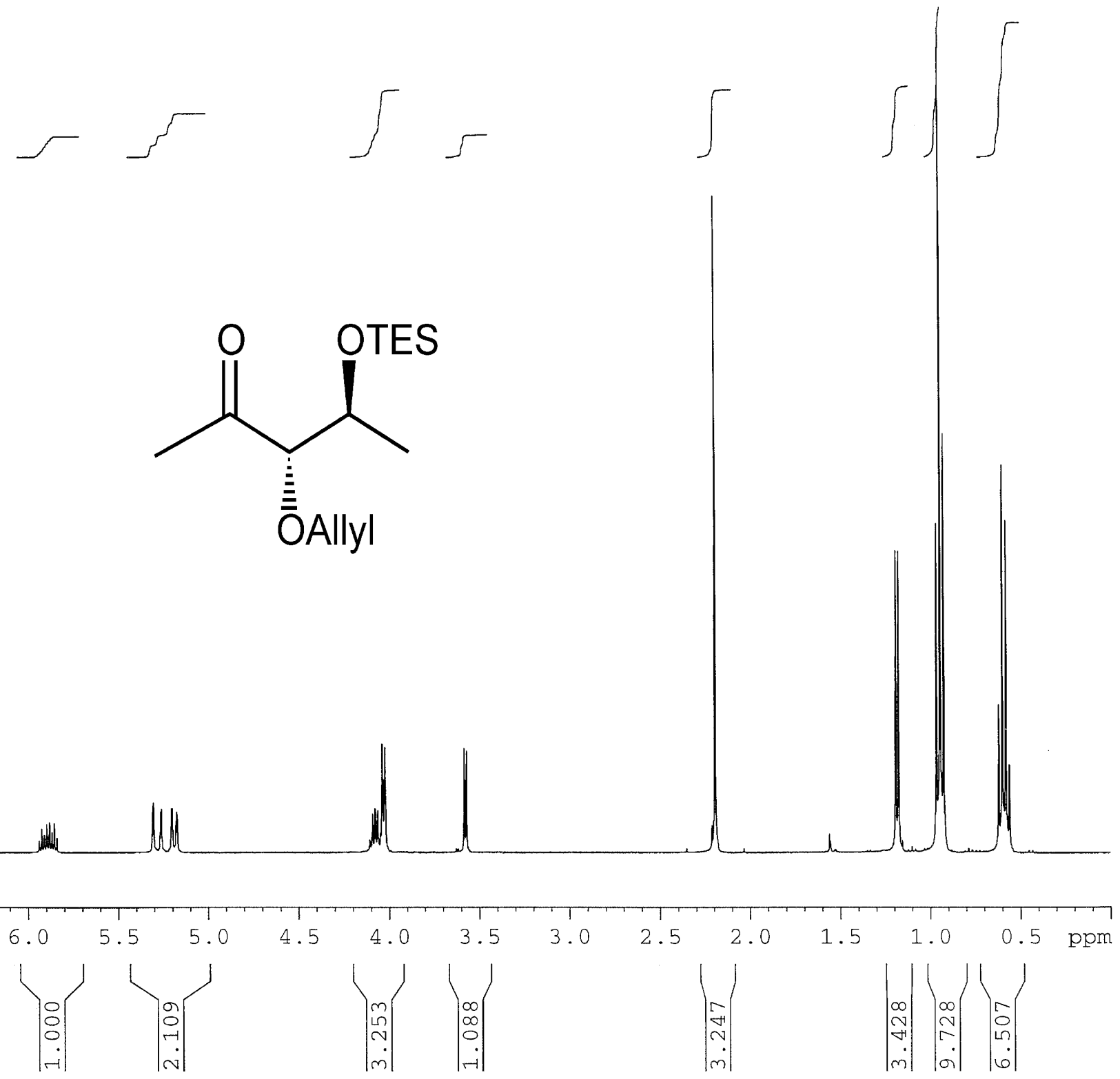




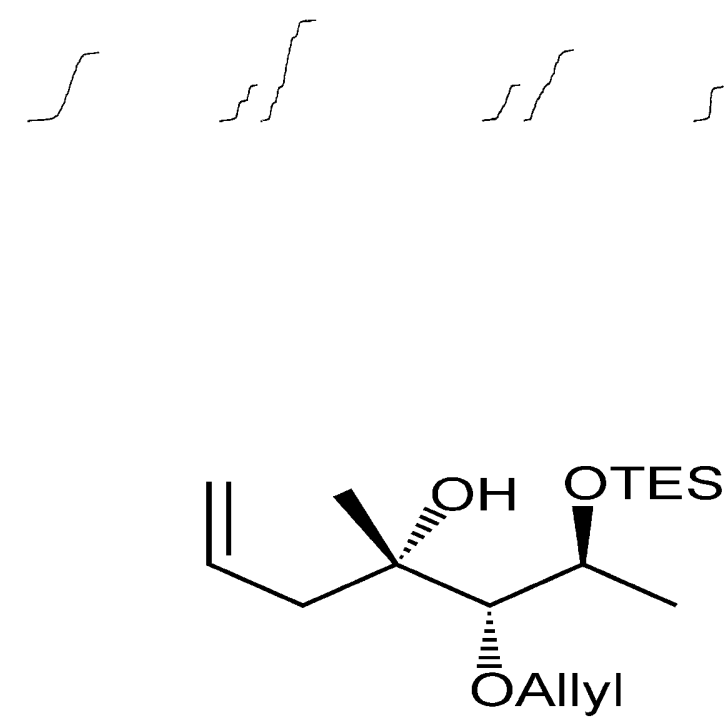

16

8.5

8.0

7.5

7.0

6.5
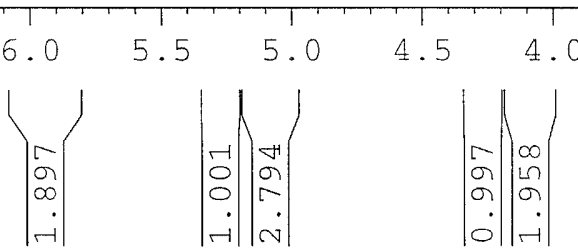

4

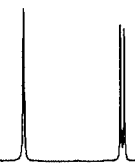

$\frac{11}{\infty}$
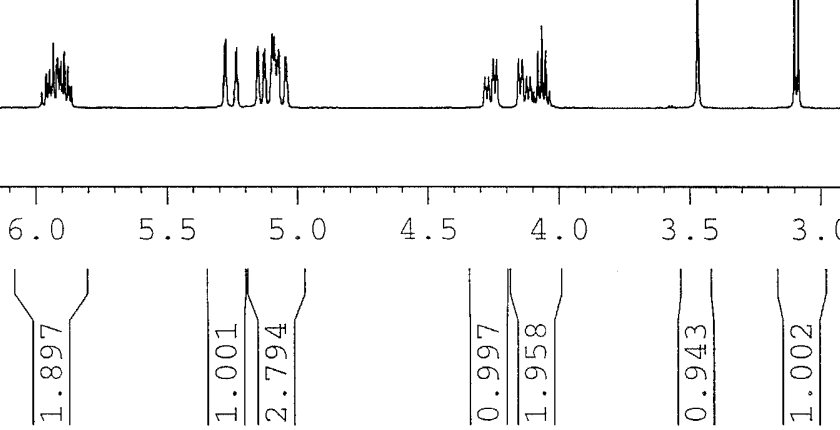

2.5
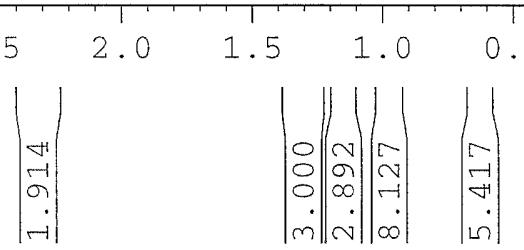


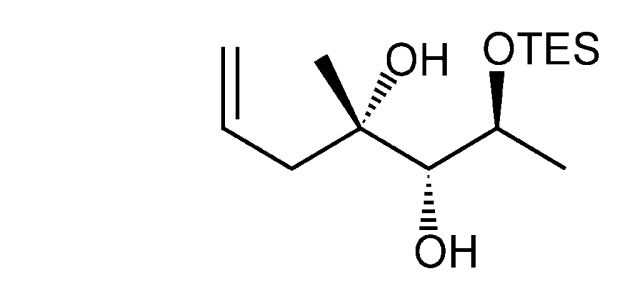

of 


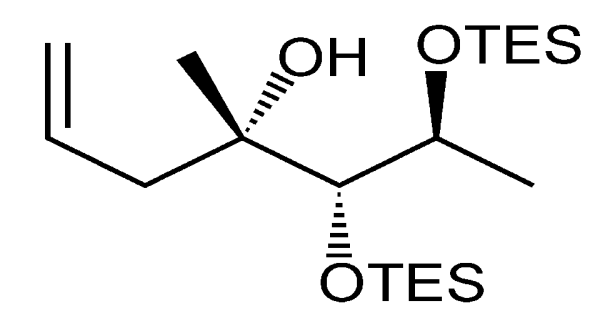

17 

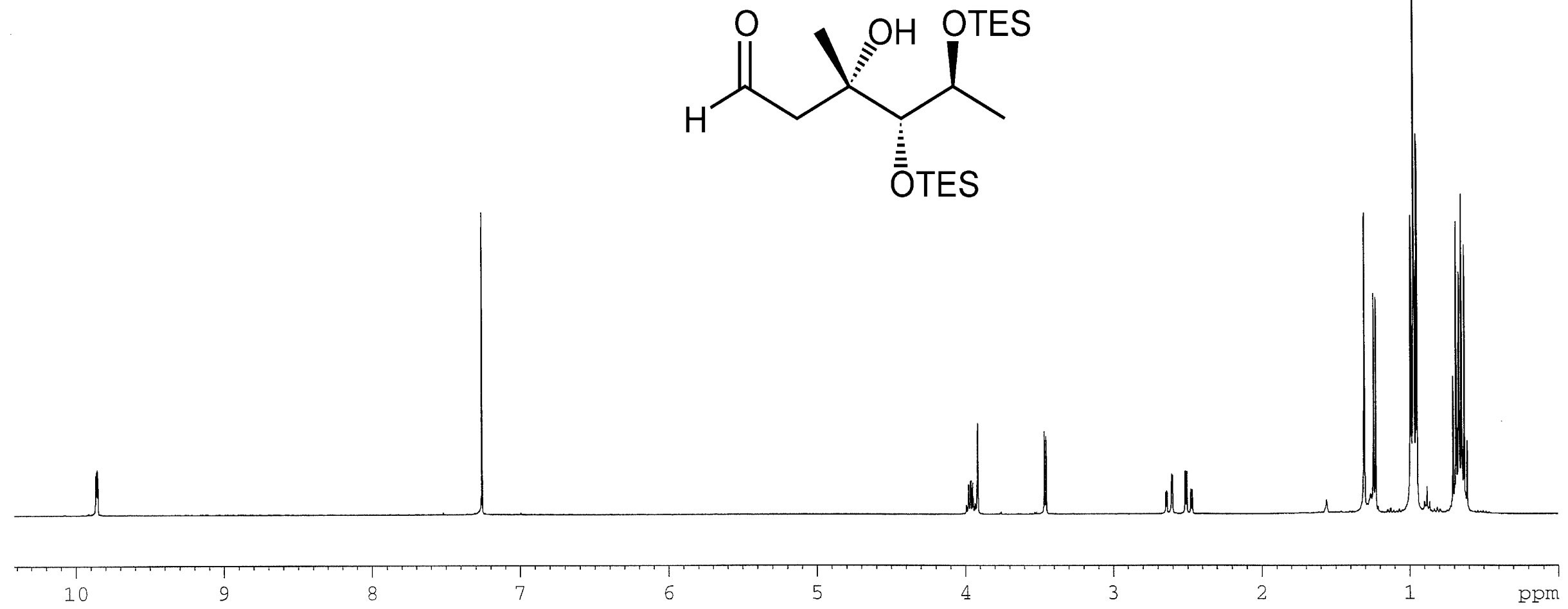

8

6

5

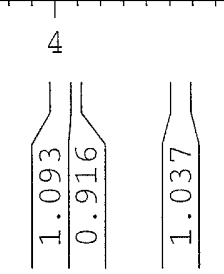

3

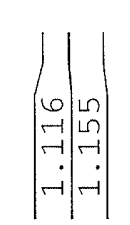

2

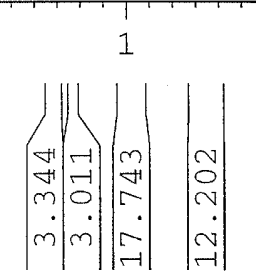




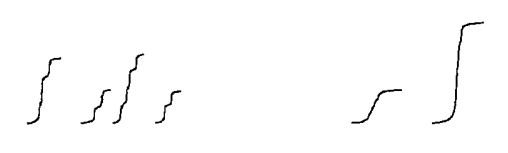

(I,

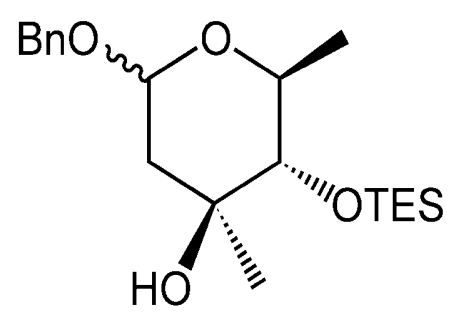

$\frac{\infty}{\infty}$

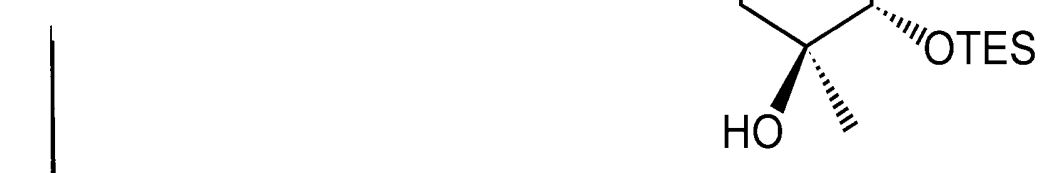

$\begin{array}{llll}9.0 & 8.5 & 8.0 & 7.5\end{array}$

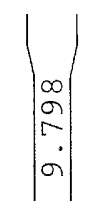

$\begin{array}{lll}6.5 & 6.0 & 5.5\end{array}$

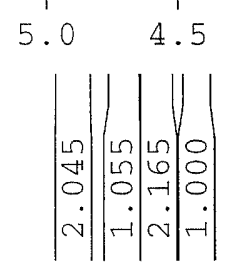

4.0
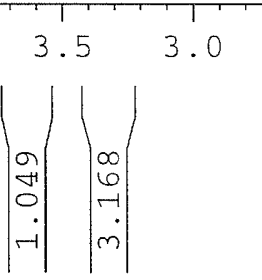

2.5

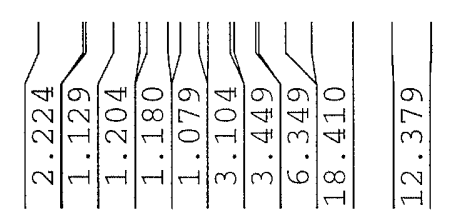




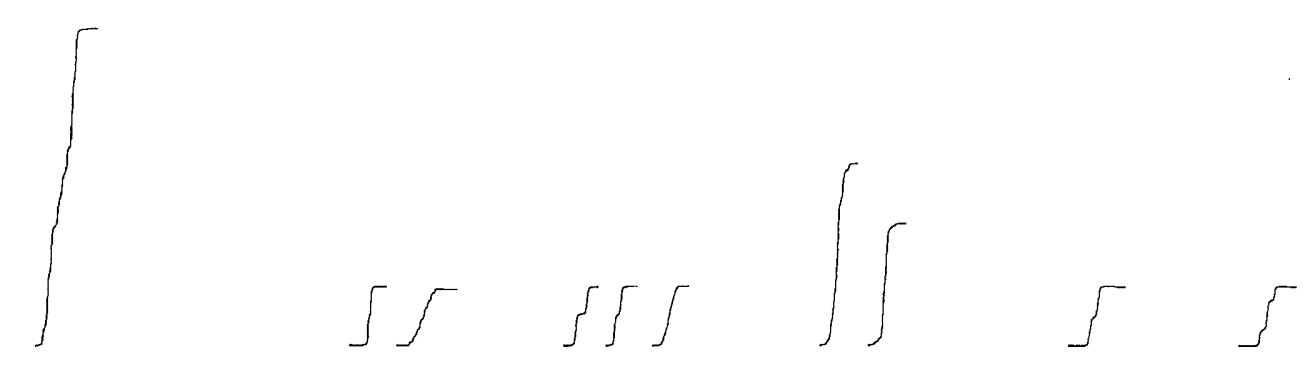<smiles>CC([OH2+])[C@@H](O[GaH2])C(=O)N1C(=S)OC[C@H]1P(=O)(O)O</smiles>
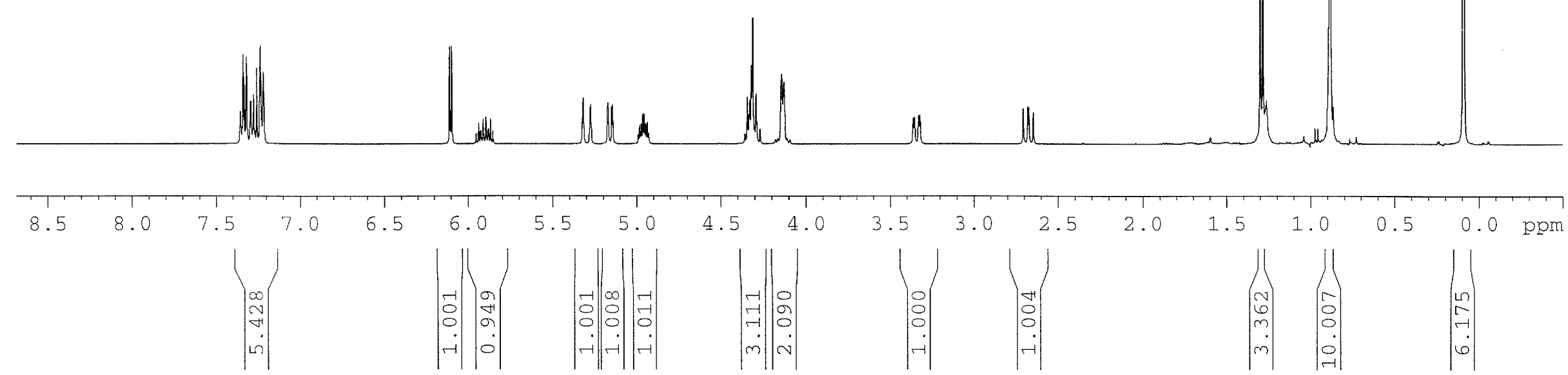


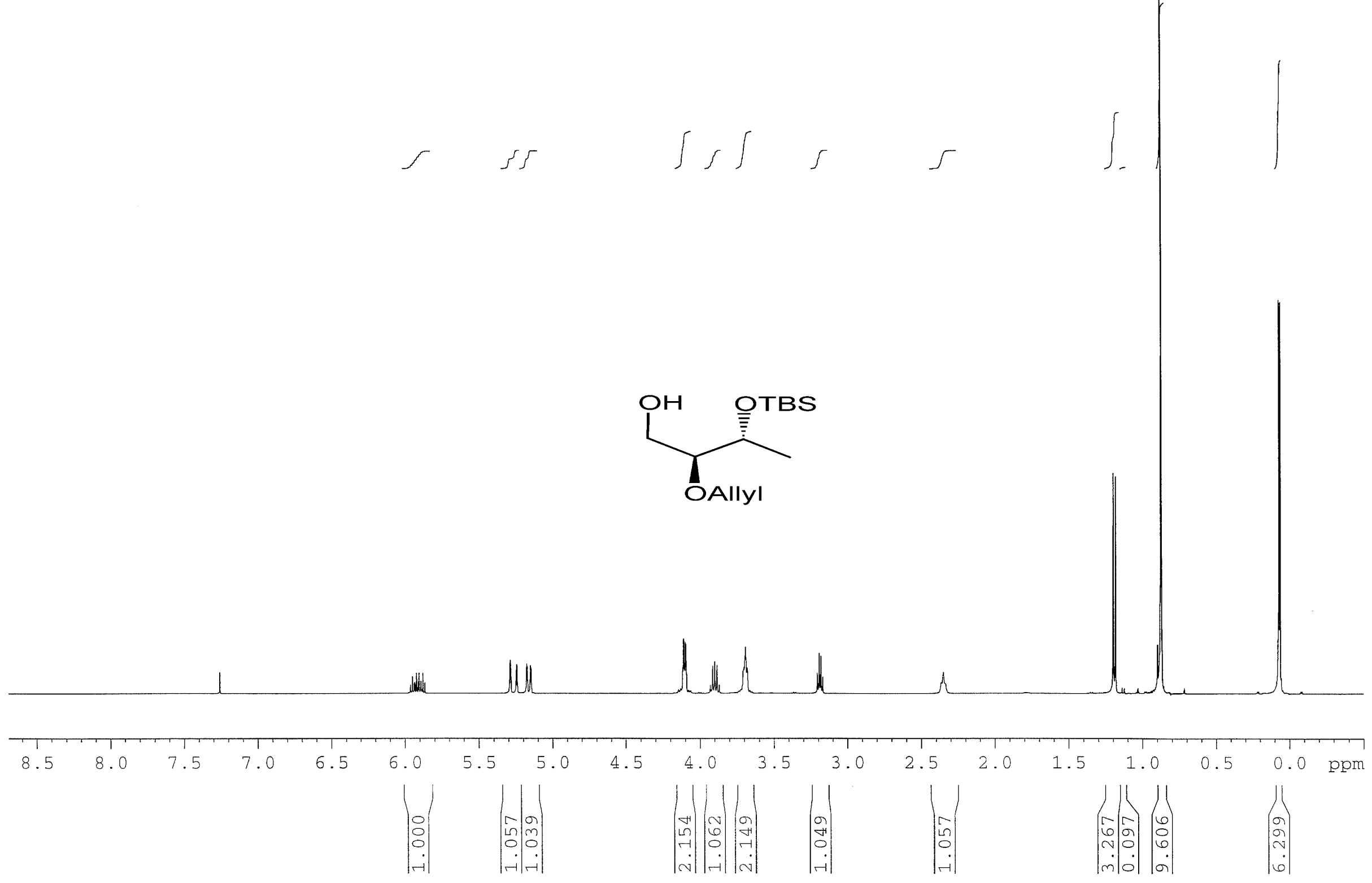




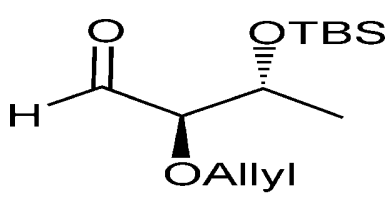

19
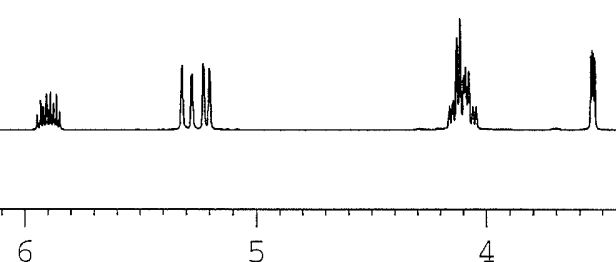

5
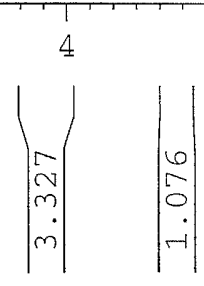

3

2

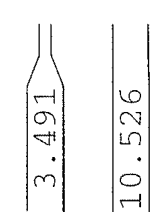




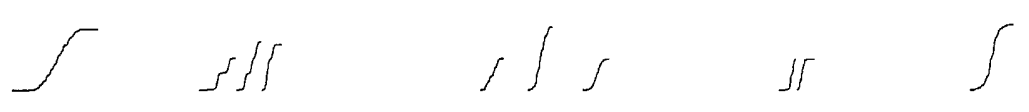
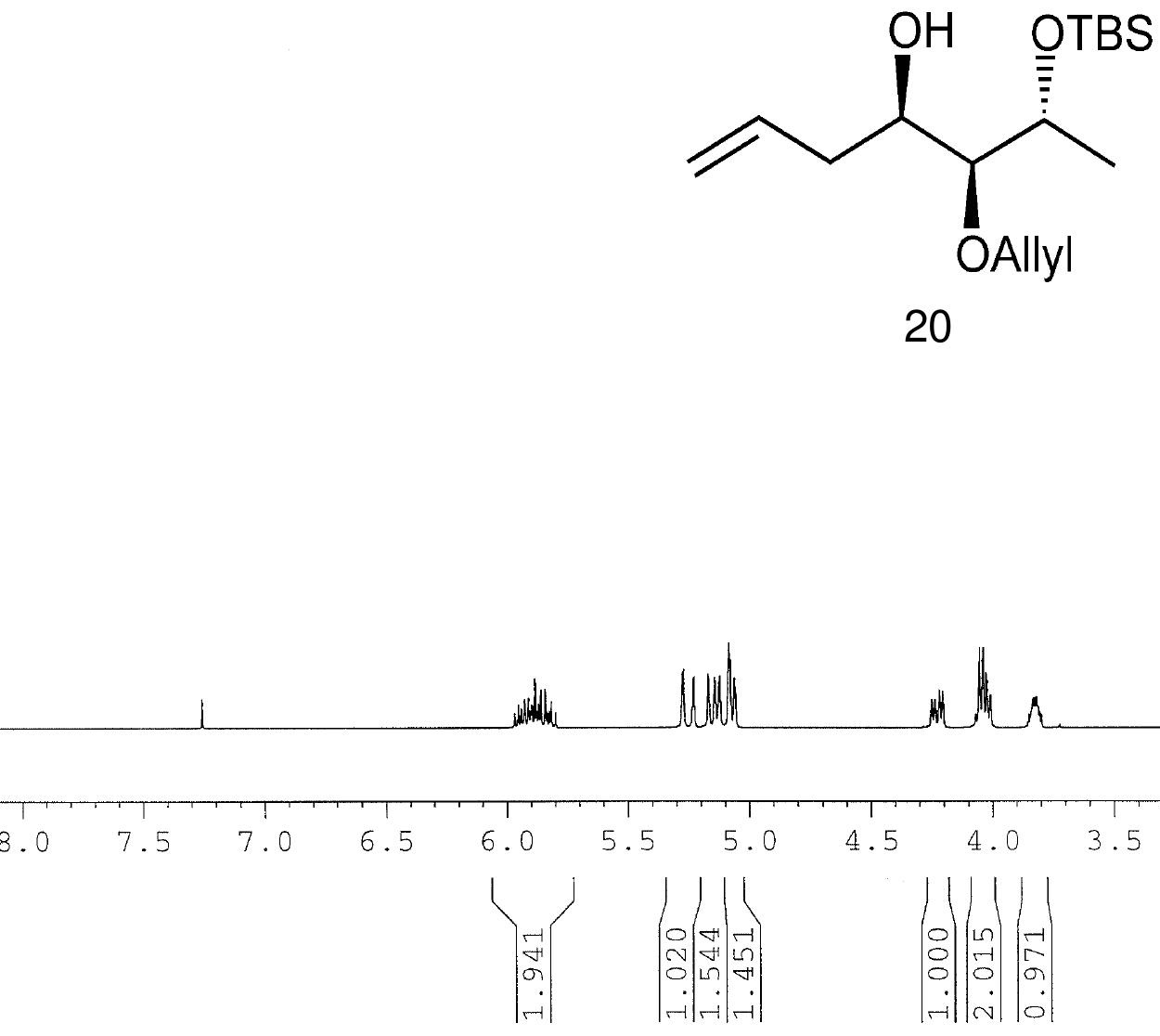

Mr

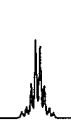

$\stackrel{\leftrightarrows}{\leftrightarrows}$

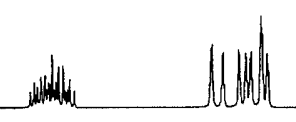

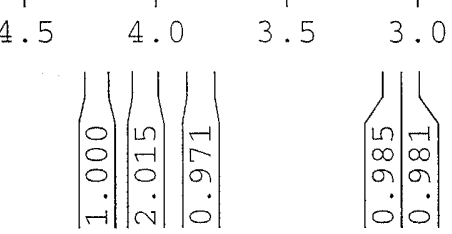

2.5

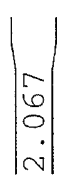

$\left|\begin{array}{c|c}0 & \\ 0 & 0 \\ 5 & \\ 0 \\ 0\end{array}\right|$

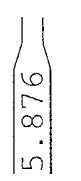




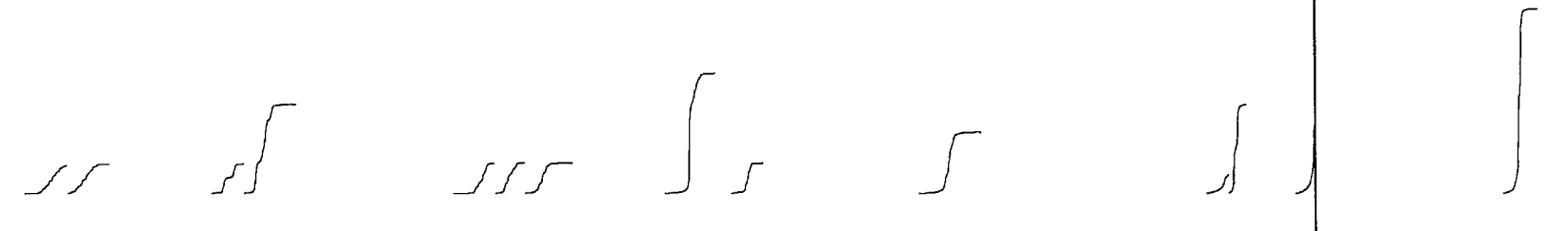<smiles>C=CC[C@@H](OC)[C@@H](O[GaH2])[C@H](C)[SeH]</smiles>

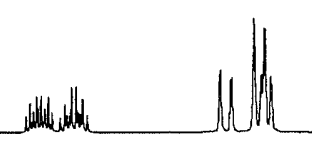
H.

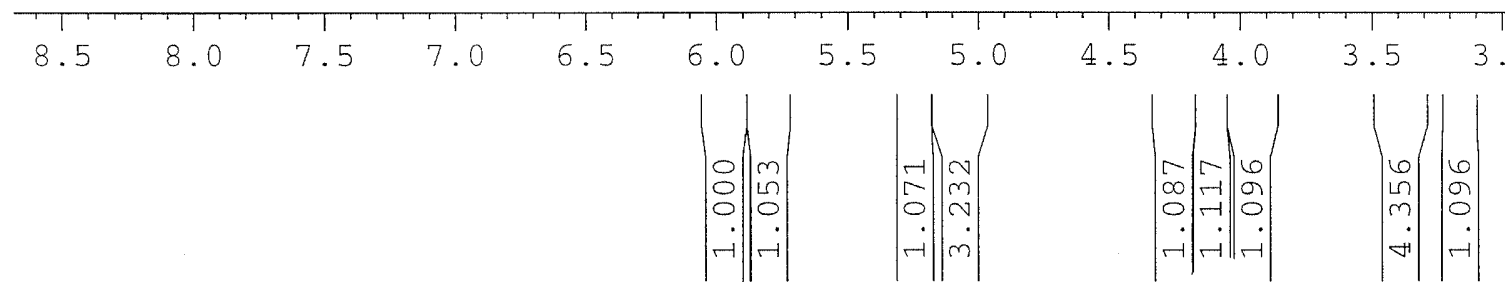





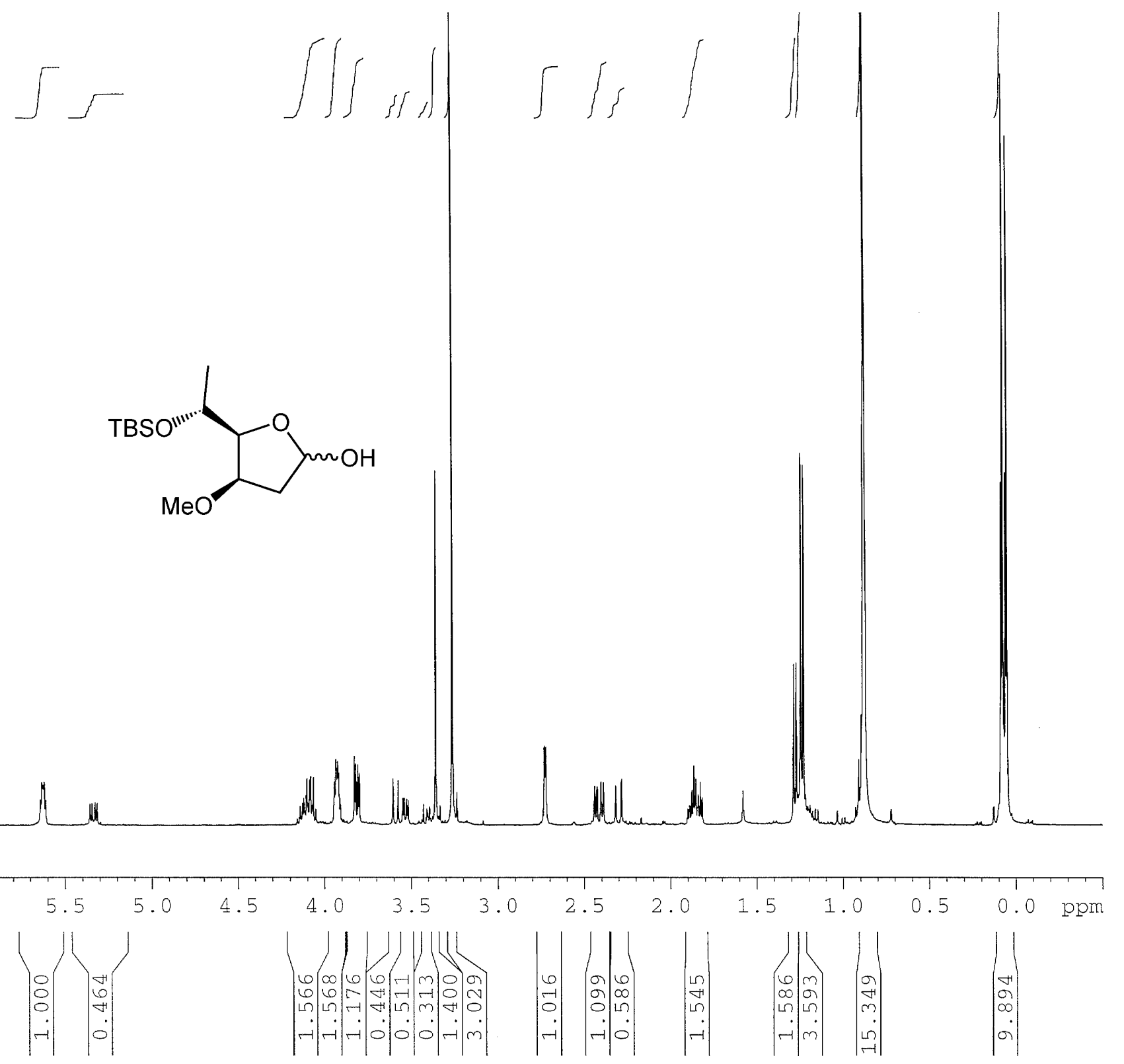




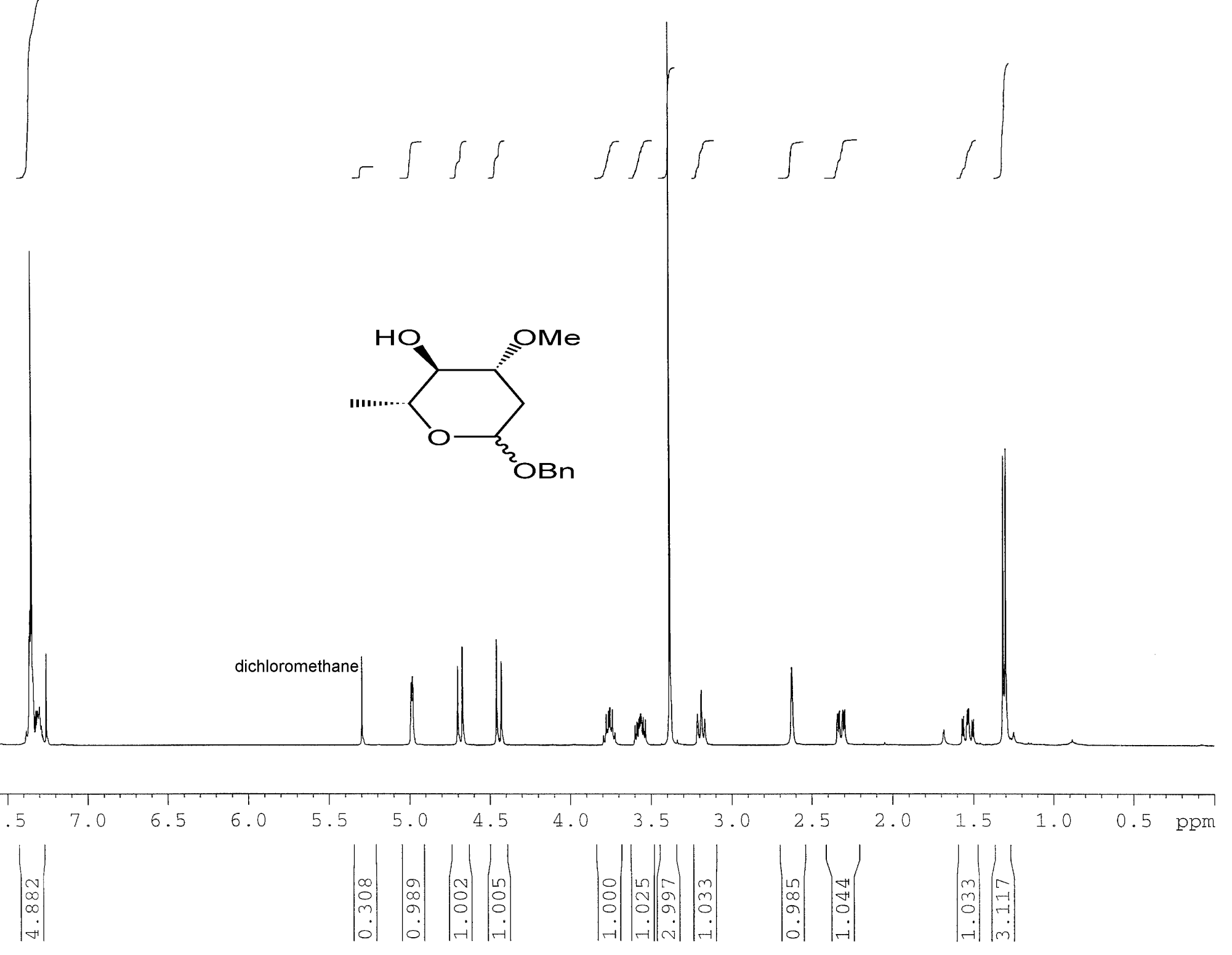



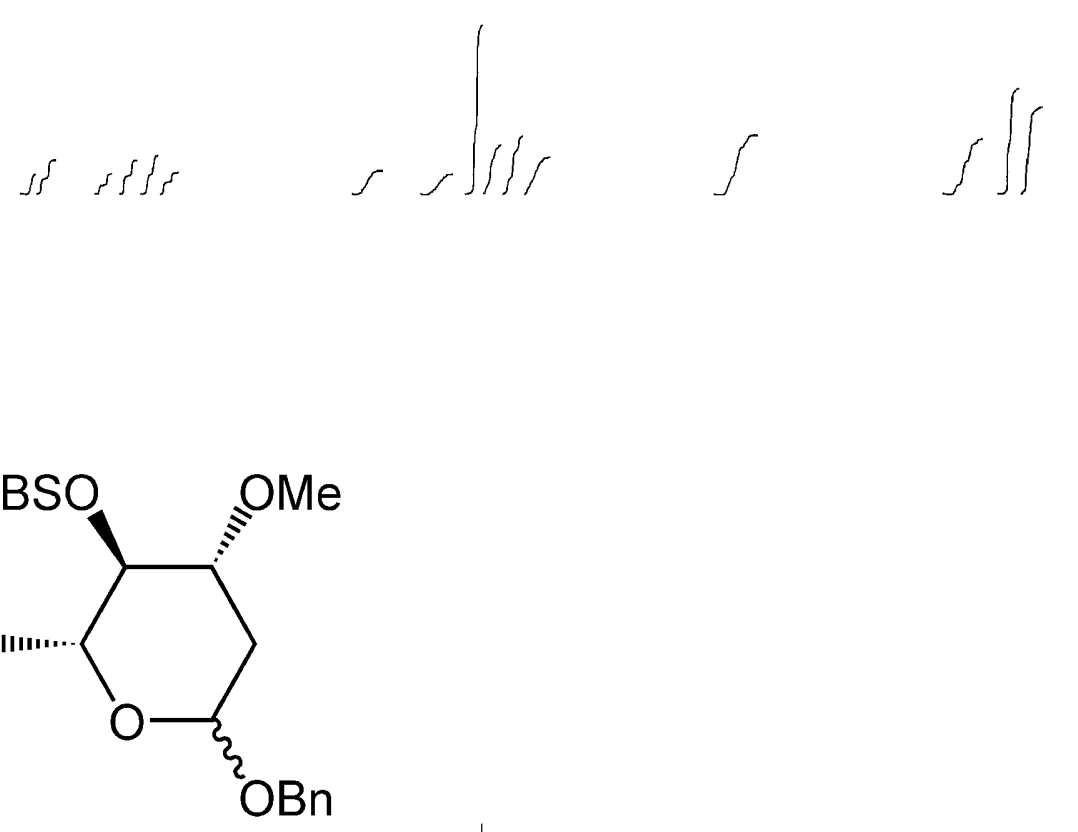

స్లి

HLallduld
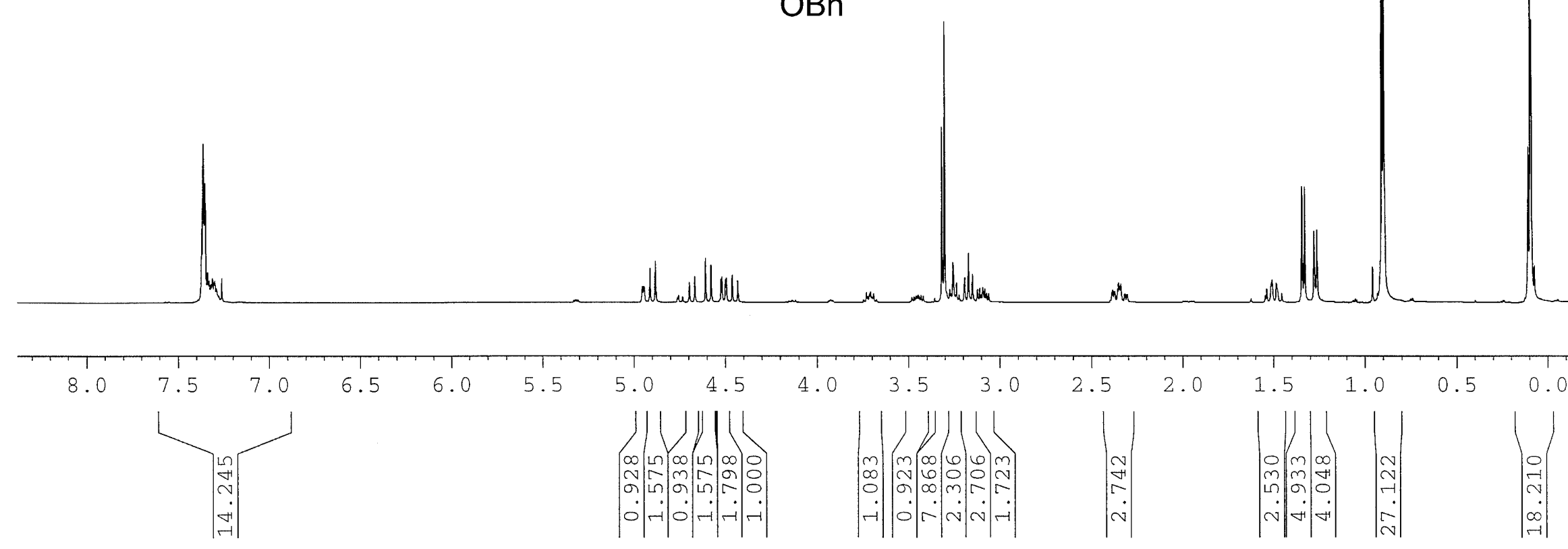


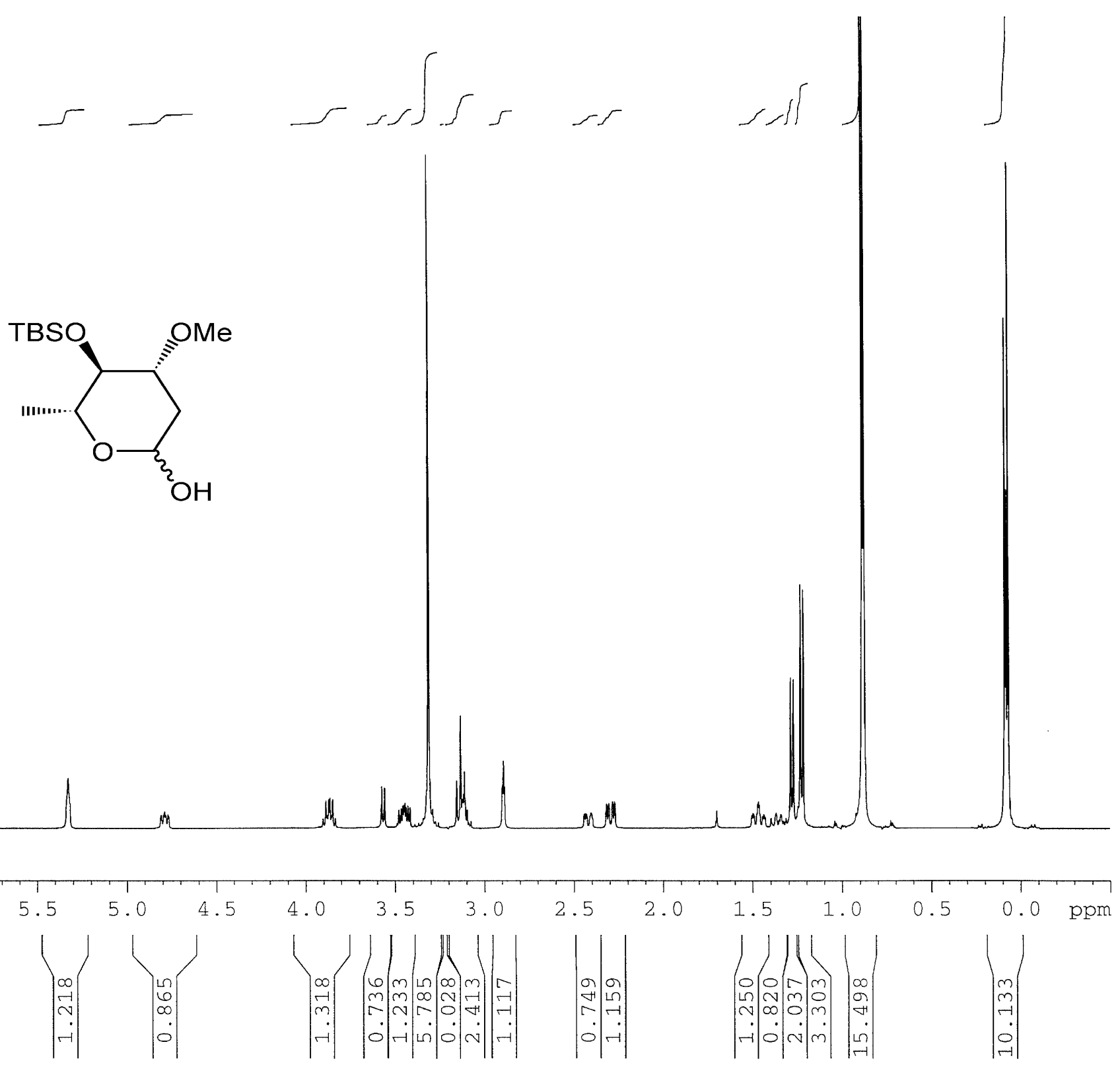

